\title{
The response of rat and human uterus to oxytocin from different gestational stages in vitro
}

\author{
Mohammed F. Alotaibi \\ Department of Physiology, College of Medicine, King Saud University and King Khalid University Hospital, P.O. Box 2925, \\ Riyadh 11461, Kingdom of Saudi Arabia
}

\begin{abstract}
Oxytocin (OT) and oxytocin receptors (OTRs) play essential roles in parturition and the effect of OT on uterine contractility is greatly influenced by the expression of OTRs in myometrium. We investigated the effect of OT on uterine strips isolated from non-pregnant, late-pregnant, termpregnant, and labouring rats and from labouring and non-labouring women. Longitudinal uterine strips (from each gestational stage) were dissected and mounted vertically in an organ bath setup system and challenged with $5 \mathrm{nM}$ OT and the effect was investigated on uterine contractility. In other experiments, phospholipase C (PLC), prostaglandin H synthase-2 (PGHS-2), and calciumactivated chloride channels (CaCCs) were blocked and the effect of OT was tested in labouring rats. OT stimulated the labouring uterus with greater force compared to other gestations in rats and also augmented the uterine force in labouring women compared to the non-labouring. However, blocking the PLC, PGHS-2, and CaCCs significantly reduced the OT-induced force increase in labouring rats. These data suggest that as labour approaches, the sensitivity of the uterine tissues to OT is greatly enhanced concomitant with the increased expression of OTR to ensure strong and adequate uterine contractions essential for the normal delivery and to prevent the postpartum haemorrhage.
\end{abstract}

Key words: Oxytocin — Labouring - Gestations - CaCCs - PGHS-2 - PLC

\section{Introduction}

Throughout the journey of pregnancy, the uterus exhibits a relatively quiescent organ and responds to a low level of uterotonins until parturition approaches. So far, the exact mechanisms triggering the onset of labour are not fully understood and during labour the uterus becomes a very active organ being very sensitive to oxytocin (OT). OT is a neuropeptide hormone which plays essential roles in labour and lactation and stimulation of the uterus by OT during labour is mostly inevitable. OT is synthesised in the hypothalamus and released into the circulation from its store in the posterior pituitary gland. However, evidence confirmed the synthesis of OT in some peripheral tissues such as myometrium, endometrium, corpus luteum, placenta, and amnion (Gimpl and

Correspondence to: Mohammed F. Alotaibi, Department of Physiology, College of Medicine, King Saud University and King Khalid University Hospital, P.O. Box 2925, Riyadh 11461, Kingdom of Saudi Arabia

E-mail: mfalotaibi@ksu.edu.sa
Fahrenholz 2001) to facilitate the local regulation and timing of labour contractions (Mitchell and Chibbar 1994). OT is not important for the pregnant uterus only but its role is vital in the non-pregnant uterine tissues during sperm transport (de Vries et al. 1990; Lyons et al. 1991) and menstruation (Maggi et al. 1992). In the non-pregnant uterus, the expression of uterine oxytocin receptors (OTRs) is fluctuating throughout the menstrual cycle. Lee et al. (1998) found higher OTRs expression during preovulatory phase than the postovulatory phase whereas others found significantly higher OTRs during the late-luteal phase and menstruation than the follicular phase (Maggi et al. 1992; Einspanier et al. 1998). Throughout pregnancy, the expression of OTRs increases progressively as the stages of pregnancy progresses and peaks at parturition (Fuchs et al. 1984; Arthur et al. 2008).

The OTRs belong to rhodopsin type-1 G-protein coupled receptor (GPCR) superfamily. In myometrium, $\mathrm{G}_{\alpha q / 11}$ proteins are coupled to phospholipase C (PLC) (Phaneuf et al. 1993), which cleaves the phosphatidylinositol biphosphate $\left(\mathrm{PIP}_{2}\right)$ into two second messengers; inositol-trisphosphate $\left(\mathrm{IP}_{3}\right)$ and diacylglycerol (DAG) which control 
the mobilisation of $\mathrm{Ca}^{2+}$ from the sarcoplasmic reticulum (SR) and the activation of PKC, respectively (Gimpl and Fahrenholz 2001). $\mathrm{Ca}^{2+}$ influx and release from the SR stimulate the $\mathrm{Ca}^{2+}$-calmodulin complex and the activation of myosin light chain kinase. This mechanism causes uterine smooth muscles contraction as well as contraction of mammary myoepithelial smooth muscles leading to milk let-down (Gimpl and Fahrenholz 2001). OT can also act on voltage-gated $\mathrm{Ca}^{2+}$ channels (VGCCs) resulting in membrane depolarization and $\mathrm{Ca}^{2+}$ influx (Sanborn et al. 2005). Moreover, OT can activate the calcium-activated chloride channels (CaCCs) resulting in chloride efflux and membrane depolarization, thereby allowing $\mathrm{Ca}^{2+}$ influx via calcium channels and further enhances the contraction (Adaikan and Adebiyi 2005). In addition, OTRs can activate the mitogen-activated protein kinase (MAPK) which activates the cytosolic phospholipase A2 $\left(\mathrm{cPLA}_{2}\right)$ (Molnár et al. 1999). This enzyme is essential for the hydrolysis of the membrane phospholipids and the liberation of arachidonic acid resulting in the increased production of prostaglandin (PG) via prostaglandin endoperoxide- $\mathrm{H}$ synthases-2 (PGHS-2) (Soloff et al. 2000). It has been shown that $\mathrm{PGF}_{2 a}$ is significantly released after stimulation by OT in pregnant and non-pregnant uteri (Franczak et al. 2004) suggesting a strong interaction between OT and PG in synergizing the force of uterine contraction. The activation of MAPK pathways, increased production of PG in conjunction with the membrane depolarization and increased intracellular $\mathrm{Ca}^{2+}$ concentration which all together contribute to the effect of OT in augmenting the force of uterine activity. The objectives of the present study were to examine and compare the effect of OT on uterine strips obtained from different gestational stages in humans and rats in vitro, and to investigate the possible physiological mechanisms of OTinduced uterine activity in labouring animals.

\section{Materials and Methods}

\section{Human and animal uterine tissues}

Experiments were performed on intact uterine tissues isolated from women and rats. Biopsies of human myometrial tissues were obtained from the upper lip of the lower uterine segment from two groups of women; labouring women undergoing emergency caesarean section (CS) or non-labouring women undergoing planned elective CS ( $n=5$ each). All labouring women were in the full term of pregnancy (week 40-41) whereas all the non-labouring women were in the late-pregnancy before the full term (weeks 38-39). The indications for the emergency CS were foetal distress and failure to progress while the indications for the planned elective CS were previous CS, breech baby or previous traumatic vaginal delivery. The mean maternal age at the time of delivery for the labouring women was $30 \pm 6$ years and $32 \pm 5$ years for the non-labouring women. The average parity for all women in both groups was 1 (range $0-2$ ). All women provided written informed consent at Liverpool Women's Hospital, UK and ethical approval was sought and granted by the Local Research Ethics Committee. Animal myometrial tissues were obtained from female Wistar rats at the following gestational stages: virgin non-pregnant (180-200 g), late-pregnant (17-18 day of gestation), full term-pregnant (22 day of gestation) and labouring (after the delivery of the $1^{\text {st }}$ pup). In rats, parturition occurs on day 22.

Animals were humanely killed by cervical dislocation under $\mathrm{CO}_{2}$ inhalation in accordance with the UK Home Office legislation and guidelines. The uteri were removed and immediately placed into physiological saline solution (PSS) containing (in mM): $154 \mathrm{NaCl}, 5.6 \mathrm{KCl}, 1.2 \mathrm{MgSO}_{4}$, 7.8 glucose, 10.9 HEPES and $2.0 \mathrm{CaCl}_{2}$, $\mathrm{pH}$ 7.4.

\section{Tissue dissection and preparation of uterine strips}

Longitudinal uterine strips $(2 \times 10 \mathrm{~mm})$ were dissected from rats (with intact endometrium) and from women (without endometrium). To avoid any discrepancy in the results amongst uterine samples, all strips were carefully measured before experiments to obtain even size and all animal strips were dissected from the ovarian ends (Alotaibi 2016).

\section{Measurement of tension and experimental protocols}

Uterine strips were mounted in an organ bath chambers as previously described (Alotaibi et al. 2015). Briefly, strips were vertically placed into $5 \mathrm{ml}$ jacketed organ bath chambers (Linton Instruments, UK), filled with buffered PSS solution pre-bubbled with $95 \% \mathrm{O}_{2}$ and $5 \% \mathrm{CO}_{2}$ at $37^{\circ} \mathrm{C}$. One end of the strip was attached to a fixed hook using a silk suture and the other end was attached to an isometric force transducer (Letica Scientific Instrument, LSI) connected to data acquisition system with DataTrax V.2 software (World precision instruments Inc., USA).

All uterine strips were stretched to a $1 \mathrm{~g}$ standard resting tension (Alotaibi et al. 2015) and allowed to equilibrate for at least 30 minutes to obtain regular uterine contractions before adding any drug. After obtaining regular spontaneous uterine contractions, OT was added directly to the PSS for 20 minutes and its effect was monitored. In other experiments, uterine strips were stimulated with OT and the blockers were added in the continued presence of OT.

\section{Drugs and solutions}

All chemicals used in this study were of analytical grade and obtained from Sigma Aldrich, UK, unless stated 
otherwise. All stock solutions were made according to the manufacturer's guidelines. The stock solution of OT was made using $\mathrm{dH}_{2} \mathrm{O}$ and a final concentration of OT (5 nM) was used in the study (Alotaibi et al. 2015). Nimesulide is a potent selective blocker for PGHS-2 which was dissolved in dimethyl sulfoxide (DMSO), and used at final concentration of $10 \mu \mathrm{M}$ (Connolly et al. 1998). Niflumic acid (NFA) is a relatively selective blocker for the $\mathrm{CaCC}$ and it was dissolved in DMSO and used at a final concentration of $10 \mu \mathrm{M}$ (Jones et al. 2004). U-73122 is a selective potent blocker for PLC and it was obtained from Calbiochem ${ }^{\circledast}$ and used at a final concentration of $10 \mu \mathrm{M}$ (Trujillo et al. 2000).

\section{Statistical and data analysis}

Data were analyzed using Microcal Origin Software (OriginLab, USA, V.9). Area under the curve (AUC) was calculated as the main parameter to assess the entire uterine contractility (Alotaibi et al. 2015; Alotaibi 2016). Data were analysed as follows: Spontaneous contractile activity during the last 10 minutes (in rats) and 20 minutes (in women) preceding the application of OT was calculated and taken as $100 \%$ control. The first 10 minutes (in rats) and 20 minutes (in women) after the application of OT was then analyzed and expressed as a percentage of this control. In other experiments where blockers were used, data were analysed by calculating the last 10 minutes of contractile activity in the continued presence of OT alone (100\% control) and compared with the last 10 minutes during the continued presence of OT and blockers simultaneously. Data are presented as mean \pm standard error of the mean (SEM) using one-way analysis of variance (ANOVA) with post hoc Bonferroni test only when the ANOVA revealed a statistical significant difference $(p<0.05) . n$ represents the number of uterine samples, one from each animal or women.

\section{Results}

\section{The effect of oxytocin on rat uterine contractility}

Stimulating the uterine strips with $5 \mathrm{nM}$ OT produced a potentiating effect on spontaneous uterine activity in all samples tested irrespective of the gestational stages, however, the response to OT is gestational-dependent. In non-pregnant uterus $(n=6)$, addition of $5 \mathrm{nM}$ OT significantly increased the AUC to $282 \pm 6 \%$ compared to $100 \%$ spontaneous uterine activity (Fig. 1A, $p<0.01)$. In late-pregnant uterus $(n=6)$, the AUC increased to $194.7 \pm 4 \%$ (Fig. $1 \mathrm{~B}, p<0.01$ ). In termpregnant $(n=6)$, the AUC significantly increased to $285.6 \pm$ $3 \%$ (Fig. $1 \mathrm{C}, p<0.01)$. However, in labouring uterus $(n=6)$, the AUC significantly increased to $367.5 \pm 3.4 \%$ compared to $100 \%$ control spontaneous uterine activity (Fig. 1D, $p<0.01$ ).

When comparing the means of the effect of OT from different gestational stages, it is clear that OT produced the most pronounced and significant increase in force in labouring rats compared to any other gestations, whereas the effect of OT was the least in late-pregnant compared to all other gestations. Fig. 2 summarizes the effect of OT on rat uterine contractility obtained from different gestational stages with means comparison.
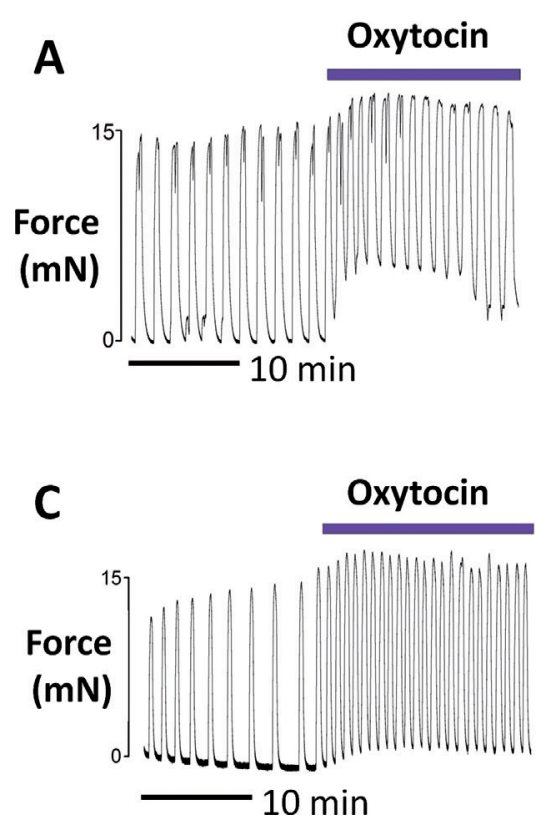

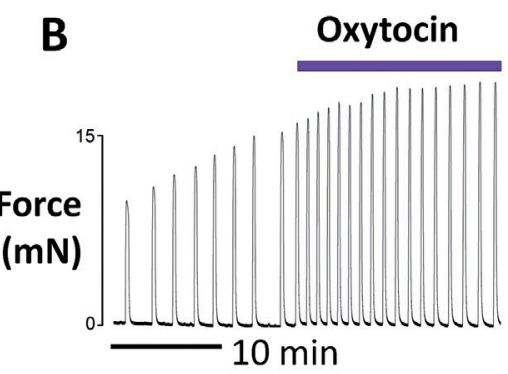

Oxytocin

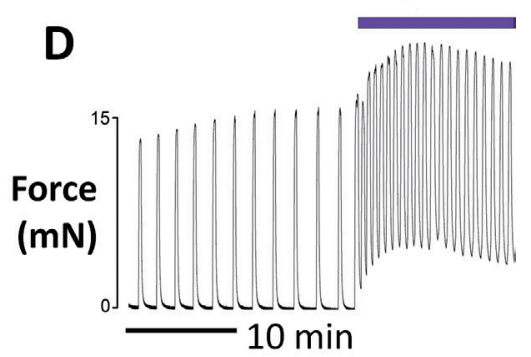

Figure 1. The effect of oxytocin on rat uterine contractility in different gestations. Original recordings showing the increase of force after addition of $5 \mathrm{nM}$ oxytocin to spontaneously contracting uterus in Non-pregnant (A), Late-pregnant (B), Term-pregnant (C), and Labouring rats (D). Note the increase in force baselines in Non-pregnant, Term-pregnant, and Labouring uterine strips compared to the Late-pregnant. 


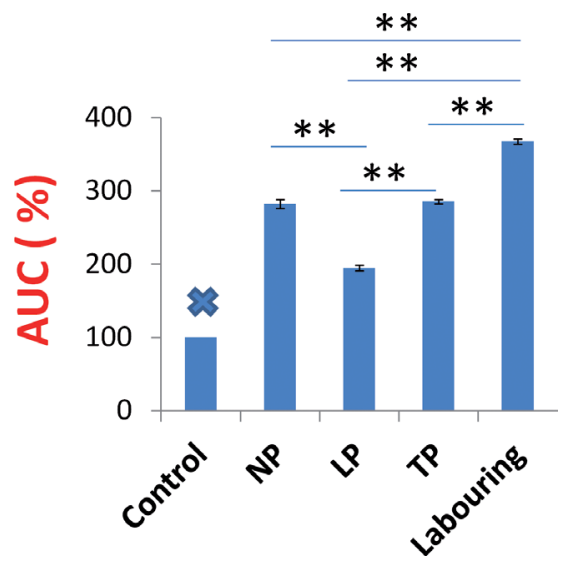

Figure 2. The effect of oxytocin on rat uterine contractility in different gestations. Bar charts showing the significant increase in $\%$ area under the curve (AUC) after addition of $5 \mathrm{nM}$ oxytocin to spontaneously contracting uterus in Non-pregnant (NP), Late-pregnant (LP), Term-pregnant (TP), and Labouring rats compared to $100 \%$ control spontaneous activity. The histograms represent AUC (mean \pm SEM), $n=6$ independent samples from each gestation. ${ }^{\mathrm{x}}$ indicates that control is significantly different from all other gestations, ${ }^{* *} p<0.01$.

The effect of oxytocin on human uterine contractility

In labouring uterus $(n=5), 5 \mathrm{nM}$ OT significantly increased the AUC to $222 \pm 3.5 \%$ compared to $100 \%$ spontaneous uterine activity (Fig. 3A, $p<0.01$ ). In non-labouring uterus $(n=5)$, OT significantly increased the AUC to $143 \pm 2 \%$ compared to $100 \%$ spontaneous uterine activity (Fig. 3B, $p<0.01)$. Figure 3C summarizes the comparison between the means with significant values.

\section{The effect of blocking PLC, PGHS-2, and CaCCs on $O T$-induced uterine contractility in labouring rats}

To investigate the underlying mechanism of OT-induced force increase in labouring rats, important pathways were blocked including PLC, PGHS-2, and CaCCs. As shown in Fig. 4, blocking the PLC, PGHS-2, and CaCCs pathways significantly decreased the force produced by OT. Inhibiting the PLC with U-73122 significantly decreased the force produced by OT to $77 \pm 5.5 \%$ compared to $100 \%$ control before adding the drug $(p<0.05)$. Blocking the PGHS-2 with nimesulide significantly decreased the force produced by OT to $44 \pm 4 \%$ compared to $100 \%$ control before adding the drug $(p<0.01)$. However, blocking the CaCCs with niflumic acid significantly decreased the force produced by OT to $59 \pm 3 \%$ compared to $100 \%$ control before adding the blocker $(p<0.01)$.

\section{Discussion}

In this study we examined the effect of OT on rat and human uterine strips obtained from different gestational

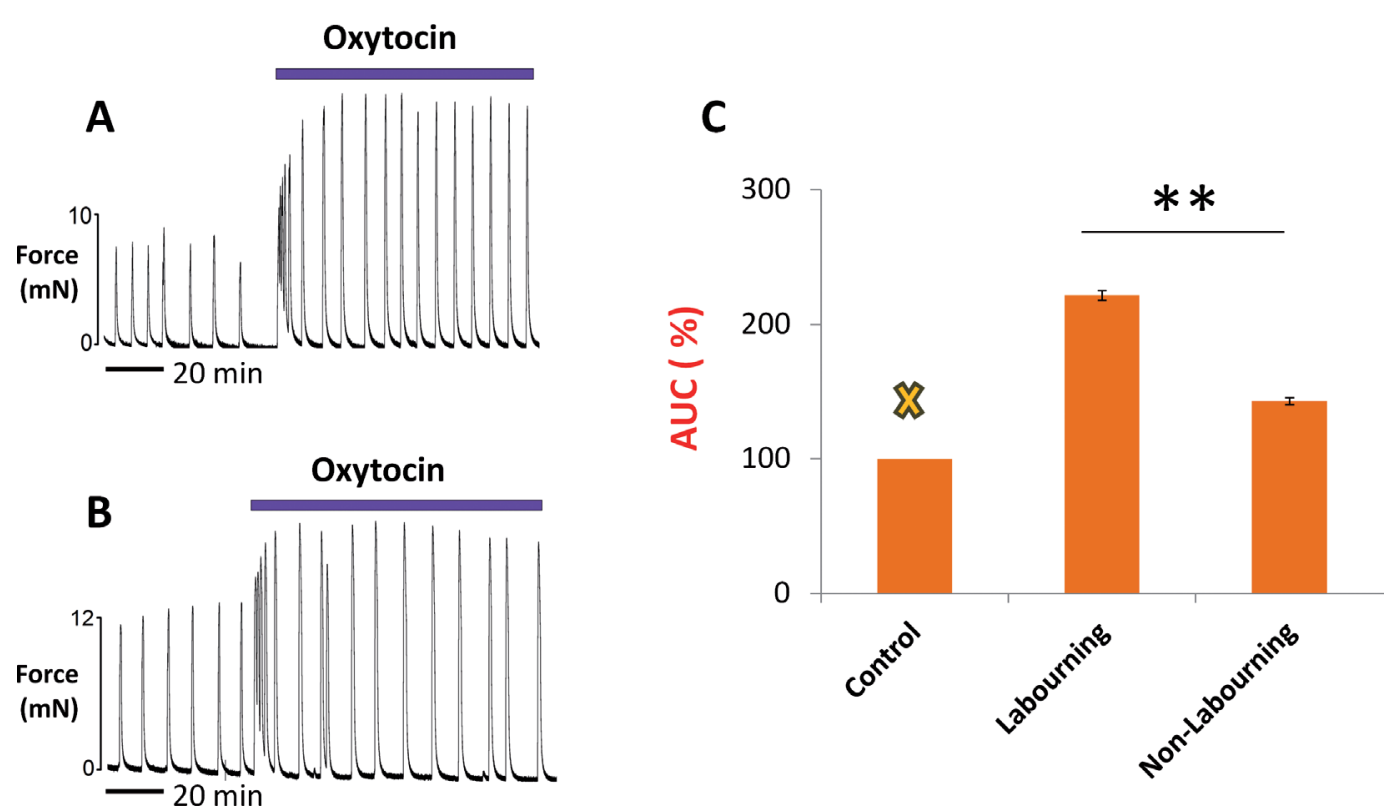

Figure 3. The effect of oxytocin on human uterine contractility in different gestations. Original recordings showing the increase in force after addition of $5 \mathrm{nM}$ oxytocin to spontaneously contracting uterus in Labouring (A) and Non-labouring (B) women. C. Bar charts showing the significant increase in \% area under the curve (AUC) after addition of OT to spontaneously contracting uterus in Labouring and Non-labouring human uterus. ${ }^{\mathrm{x}}$ indicates that control is significantly different from all other gestations, ${ }^{* *} p<0.01$. 


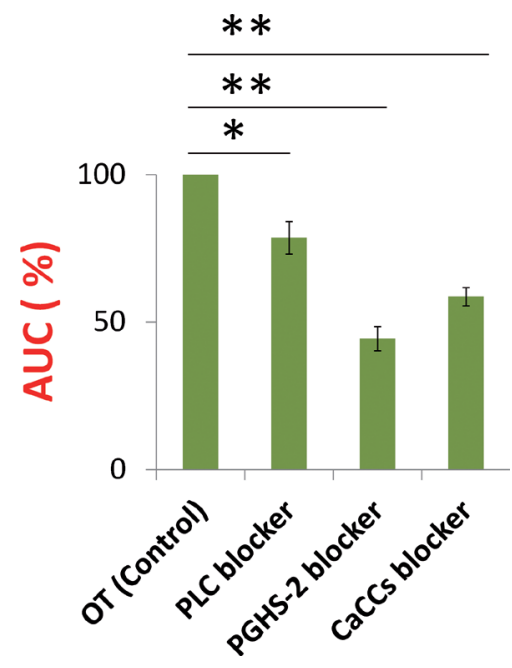

Figure 4. The effect of blocking PLC, PGHS-2, and CaCCs on oxytocin (OT)-induced uterine contractility in labouring rats. Bar charts showing the significant decrease in \% area under the curve (AUC) after addition of $10 \mu \mathrm{M}$ PLC blocker (U-73122), $10 \mu \mathrm{M}$ PGHS-2 (nimesulide), and $10 \mu \mathrm{M}$ CaCCs blocker (niflumic acid) on OT-induced uterine contraction in Labouring rats. The histograms represent AUC (mean $\pm \mathrm{SEM}), n=4$ independent samples. ${ }^{* *} p<0.01,{ }^{*} p<0.05$.

stages using the previously established perfusion system (Polacek and Daniel 1971). We show that the effect of OT on spontaneous uterine contractility is a gestationaldependent and is more pronounced in labouring uterus than in uteri from other gestational stages. The effect of OT on uterine contractions depends mainly on the level of OTRs present in uterine compartments (Gimpl and Fahrenholz 2001). It has been shown that OTRs are expressed in pregnant and non-pregnant uteri (Lefebvre et al. 1994; Arthur et al. 2008) and that their expression is significantly increased as pregnancy progresses and reached their maximal peak at parturition (Soloff et al. 1979; Fuchs et al. 1984). We have found that OT was able to stimulate uterine contractions in all uterine strips obtained from rats and humans regardless of the gestational stages. However, the uterine strips from the late-pregnant animals or the non-labouring human responded with less force compared to the term-pregnant or labouring rats and humans. These findings are in agreement with the previous studies which showed that the expression of OTRs mRNA was reduced in mid-pregnant rat uterus compared to the non-pregnant but increased significantly as labour approaches (Arthur et al. 2008). In addition, studies have found a dramatic increase in uterine OTRs mRNA ( 150 fold) very close to labour which preceded the increase in OTRs expression (Soloff et al. 1979; Lefebvre et al. 1994). In addition to the increase in
OTRs, several studies have shown a significant increase in the maternal plasma OT at the onset of labour compared to the late pregnancy or before the onset of labour in both humans and animals (Fuchs et al. 1983; Higuchi et al. 1985; Fuchs et al. 1991; Olsson et al. 2003). The increase in maternal plasma OT is gradual and concomitant with the increase in OTRs as labour progresses to maintain adequate and frequent labour contractions essential for the delivery of the foetus and placenta. The level of uterine stimulant system (OTRs, prostaglandin, connexin-43) has been reported to be greatly reduced in rat uteri during early pregnancy to ensure adequate uterine quiescence and suppression of premature contractility (Alexandrova and Soloff 1980; Arthur et al. 2008).

We found that uteri from non-pregnant rats responded to OT with the same force as the uteri from the termpregnant rats and this could be attributed to the effect of estrogen on the expression of OTRs. It has been found that the expression of uterine OTRs is significantly increased in non-pregnant uterus to a level comparable to those in pregnant ones when treated with estogen (Liu et al. 1996; Engstrom et al. 1999; Richter et al. 2004). Furthermore, in pregnant rat uterus, studies have shown similar OTR expression in non-pregnant and term-pregnant uterine horns and that the estogen was the likely contributor for OTR expression in these tissues (Alexandrova and Soloff 1980). In addition, anti-estrogen compound, tamoxifen, has been found to significantly reduce uterine OTRs in pregnant rats (Murata et al. 2000). These studies support the notion that the expression of OTRs is physiologically regulated by steroid hormones (Lee et al. 1998). As term approaches, the level of estrogen increases while progesterone decreases which is necessary for the expression of uterine OTRs during labour (Murata et al. 2000). It has been demonstrated that administration of progesterone prolongs pregnancy and reduced the expression of uterine OTRs in rats (Ou et al. 1998). This may explain why uterine tissues obtained from the late-pregnant rats or non-labouring women responded with less force to OT compared to the labouring tissues.

OT/OTRs activate PLC pathways and the downstream increase in intracellular calcium concentration essential for uterine contraction (Molnár et al. 1999). We found that blocking the PLC with its specific inhibitor decreases the OT-increased uterine contraction significantly. This is consistent with some studies showing that PLC is activated by OT in pregnant and non-pregnant myometria (Phaneuf et al. 1996; Zhou et al. 2007), and our finding further confirms these results.

In labouring uteri, we found that OT produced the most significant and pronounced effect on uterine activity compared to its effect on any uterine strips obtained from other gestational stages in both rats and humans. This supports the 
notion that uterine OTRs are at their highest level in labouring uterine tissues (Fuchs et al. 1984; Kimura et al. 1996) and that uterine sensitivity to OT is markedly enhanced during labour (Gimpl and Fahrenholz 2001). Our data show that blocking the PGHS-2 (an important enzyme for PG biosynthesis) with nimesulide decreased the uterine response to OT significantly in labouring rats. Our findings are consistent with the previous studies which found that PGHS-2 was essential for the normal labour and that the level of this enzyme was found to be significantly up-regulated in human and rat uteri prior to the onset of labour possibly due to the potential stimulus of pro-inflammatory cytokines that is usually occur during normal labour (Slater et al. 1999; Arthur et al. 2008). Blocking the PGHS-2 decreased the PG biosynthesis induced by OT stimulation, and hence decreased the uterine contractions. Furthermore, Murata et al. (2000) found that injection of pregnant rat with $\mathrm{PGF}_{2 \alpha}$ significantly increased the mRNA OTRs expression in myometrium within $24 \mathrm{~h}$ of injection. In addition, $\mathrm{OT}$ is able to release arachidonic acids and $\mathrm{PGF}_{2 \alpha}$ significantly from uterine decidual cells in the labouring women than in non-labouring or non-pregnant women (Wilson et al. 1988) and this finding correlates well with the higher concentration of OTRs in labouring tissues and the strong interactions between OT and PG at the onset of labour.

Another possible mechanism by which OT augments the uterine contraction is via the activation of CaCCs. It has been demonstrated that these channels are expressed in pregnant rat myometrial tissues and OT was able to open these channels resulting in membrane depolarization (Arnaudeau et al. 1994; Adaikan and Adebiyi 2005). We found a significant decrease in force induced by OT when these channels were blocked with niflumic acid which further confirms that these channels are target for OT. Activation of CaCCs by OT would depolarize the myometrial cell membrane allowing more $\mathrm{Ca}^{2+}$ to enter the cell via VGCCs, and hence further increase the uterine contractility.

In conclusion, we presented a unique data showing that the effect of OT is pronounced in uterine tissues at labour compared to any other gestational stages. OT is a potent stimulator for the uterine smooth muscle contraction regardless of the gestational stage and this hormone is widely prescribed in clinical settings to induce the labour. However, as pregnancy progresses further, the sensitivity of uterine smooth muscles to the OT is enhanced reaching its maximum sensitivity at parturition. Maternal plasma OT also increases during labour concomitant with the increase in OTRs. This is to maintain strong uterine contractions essential for the normal labour through different molecular mechanisms including the activation of PLC, PG biosynthesis, and CaCCs. Any aberration in these pathways can partly decrease the effect of OT on uterine activity.

\section{References}

Adaikan P. G., Adebiyi A. (2005): Effect of functional modulation of $\mathrm{Ca} 2+$-activated $\mathrm{Cl}$-currents on gravid rat myometrial activity. Indian J. Pharmacol. 37, 21-25 http://dx.doi.org/10.4103/0253-7613.13850

Alexandrova M., Soloff M. S. (1980): Oxytocin receptors and parturition. II. Concentrations of receptors for oxytocin and estrogen in the gravid and nongravid uterus at term. Endocrinology 106, 736-738

http://dx.doi.org/10.1210/endo-106-3-736

Alotaibi M., Arrowsmith S., Wray S. (2015): Hypoxia-induced force increase (HIFI) is a novel mechanism underlying the strengthening of labor contractions, produced by hypoxic stresses. Proc. Natl. Acad. Sci. U. S. A. 112, 9763-9768

http://dx.doi.org/10.1073/pnas.1503497112

Alotaibi M. (2016): The effect of cinnamon extract on isolated rat uterine strips. Reprod. Biol. 16, 27-33 http://dx.doi.org/10.1016/j.repbio.2015.12.001

Arnaudeau S., Leprêtre N., Mironneau J. (1994): Chloride and monovalent ion-selective cation currents activated by oxytocin in pregnant rat myometrial cells. Am. J. Obstet. Gynecol. 171, 491-501 http://dx.doi.org/10.1016/0002-9378(94)90288-7

Arthur P., Taggart M. J., Zielnik B., Wong S., Mitchell B. F. (2008): Relationship between gene expression and function of uterotonic systems in the rat during gestation, uterine activation and both term and preterm labour. J. Physiol. (Lond.) 586, 6063-6076 http://dx.doi.org/10.1113/jphysiol.2008.164004

Connolly C., McCormick P., Docherty J. (1998): Effects of the selective cyclooxygenase-2 inhibitor nimesulide on vascular contractions in endothelium-denuded rat aorta. Eur. J. Pharmacol. 352, 53-58 http://dx.doi.org/10.1016/S0014-2999(98)00334-3

de Vries K., Lyons E. A., Ballard G., Levi C. S., Lindsay D. J. (1990): Contractions of the inner third of the myometrium. Am. J. Obstet. Gynecol. 162, 679-682

http://dx.doi.org/10.1016/0002-9378(90)90983-E

Einspanier A., Bielefeld A., Kopp J. (1998): Expression of the oxytocin receptor in relation to steroid receptors in the uterus of a primate model, the marmoset monkey. Hum. Reprod. Update 4, 634-646 http://dx.doi.org/10.1093/humupd/4.5.634

Engstrom T., Bratholm P., Christensen N., Vilhardt H. (1999): Up-regulation of oxytocin receptors in non-pregnant rat myometrium by isoproterenol: effects of steroids. J. Endocrinol. 161, 403-411 http://dx.doi.org/10.1677/joe.0.1610403

Franczak A., Wocławek-Potocka I., Oponowicz A., Kurowicka B., Kotwica G. (2004): Oxytocin stimulates prostaglandin F2alpha secretion and prostaglandin $\mathrm{F}$ synthase protein expression in porcine myometrial tissue. Reprod. Biol. 4, 177-184

Fuchs A., Goeschen K., Husslein P., Rasmussen A., Fuchs F. (1983): Oxytocin and initiation of human parturition. III. Plasma concentrations of oxytocin and 13, 14-dihydro-15-keto-prostaglandin F2 alpha in spontaneous and oxytocin-induced labor at term. Am. J. Obstet. Gynecol. 147, 497-502 
http://dx.doi.org/10.1016/0002-9378(83)90005-4

Fuchs A.-R., Fuchs F., Husslein P., Soloff M. S. (1984): Oxytocin receptors in the human uterus during pregnancy and parturition. Am. J. Obstet. Gynecol. 150, 734-741 http://dx.doi.org/10.1016/0002-9378(84)90677-X

Fuchs A.-R., Romero R., Keefe D., Parra M., Oyarzun E., Behnke E. (1991): Oxytocin secretion and human parturition: pulse frequency and duration increase during spontaneous labor in women. Am. J. Obstet. Gynecol. 165, 1515-1523 http://dx.doi.org/10.1016/S0002-9378(12)90793-0

Gimpl G., Fahrenholz F. (2001): The oxytocin receptor system: structure, function, and regulation. Physiol. Rev. 81, 629-683

Higuchi T., Honda K., Fukuoka T., Negoro H., Wakabayashi K. (1985): Release of oxytocin during suckling and parturition in the rat. J. Endocrinol. 105, 339-346 http://dx.doi.org/10.1677/joe.0.1050339

Jones K., Shmygol A., Kupittayanant S., Wray S. (2004): Electrophysiological characterization and functional importance of calcium-activated chloride channel in rat uterine myocytes. Pflügers Arch. 448, 36-43 http://dx.doi.org/10.1007/s00424-003-1224-7

Kimura T., Takemura M., Nomura S., Nobunaga T., Kubota Y., Inoue T., Hashimoto K., Kumazawa I., Ito Y., Ohashi K. (1996): Expression of oxytocin receptor in human pregnant myometrium. Endocrinology 137, 780-785 http://dx.doi.org/10.1210/endo.137.2.8593830

Lee K.-H., Khan-Dawood F. S., Dawood M. Y. (1998): Oxytocin receptor and its messenger ribonucleic acid in human leiomyoma and myometrium. Am. J. Obstet. Gynecol. 179, 620-627 http://dx.doi.org/10.1016/S0002-9378(98)70054-7

Lefebvre D., Farookhi R., Giaid A., Neculcea J., Zingg H. H. (1994): Uterine oxytocin gene expression. II. Induction by exogenous steroid administration. Endocrinology 134, $2562-2566$

Liu C., Takahashi S., Murata T., Hashimoto K., Agatsuma T., Matsukawa S., Higuchi T. (1996): Changes in oxytocin receptor mRNA in the rat uterus measured by competitive reverse transcription-polymerase chain reaction. J. Endocrinol. 150, $479-486$ http://dx.doi.org/10.1677/joe.0.1500479

Lyons E., Taylor P., Zheng X., Ballard G., Levi C., Kredentser J. (1991): Characterization of subendometrial myometrial contractions throughout the menstrual cycle in normal fertile women. Fertil. Steril. 55, 771-774 http://dx.doi.org/10.1016/S0015-0282(16)54246-0

Maggi M., Magini A., Fiscella A., Giannini S., Fantoni G., Toffoletti F., Massi G., Serio M. (1992): Sex steroid modulation of neurohypophysial hormone receptors in human nonpregnant myometrium. J. Clin. Endocrinol. Metab. 74, 385-392 http://dx.doi.org/10.1210/jcem.74.2.1309835

Mitchell B., Chibbar R. (1994): Synthesis and metabolism of oxytocin in late gestation in human decidua. Adv. Exp. Med. Biol. 395, 365-380

Molnár M., Rigó J., Romero R., Hertelendy F. (1999): Oxytocin activates mitogen-activated protein kinase and up-regulates cyclooxygenase- 2 and prostaglandin production in human myometrial cells. Am. J. Obstet. Gynecol. 181, 42-49 http://dx.doi.org/10.1016/S0002-9378(99)70434-5
Murata T., Murata E., Liu C., Narita K., Honda K., Higuchi T. (2000): Oxytocin receptor gene expression in rat uterus: regulation by ovarian steroids. J. Endocrinol. 166, 45-52 http://dx.doi.org/10.1677/joe.0.1660045

Olsson K., Bergström A., Kindahl H., Lagerstedt A. S. (2003): Increased plasma concentrations of vasopressin, oxytocin, cortisol and the prostaglandin F2a metabolite during labour in the dog. Acta Physiol. Scand. 179, 281-287 http://dx.doi.org/10.1046/j.0001-6772.2003.01178.x

Ou C.-W., Chen Z.-Q., Qi S., Lye S. J. (1998): Increased expression of the rat myometrial oxytocin receptor messenger ribonucleic acid during labor requires both mechanical and hormonal signals. Biol. Reprod. 59, 1055-1061 http://dx.doi.org/10.1095/biolreprod59.5.1055

Phaneuf S., Europe-Finner G., Varney M., MacKenzie I., Watson S., Bernal A. L. (1993): Oxytocin-stimulated phosphoinositide hydrolysis in human myometrial cells: involvement of pertussis toxin-sensitive and-insensitive G-proteins. J. Endocrinol. 136, 497-509 http://dx.doi.org/10.1677/joe.0.1360497

Phaneuf S., Carrasco M. P., Europe-Finner G. N., Hamilton C. H., Lopez Bernal A. (1996): Multiple G proteins and phospholipase C isoforms in human myometrial cells: implication for oxytocin action. J. Clin. Endocrinol. Metab. 81, 2098-2103 http://dx.doi.org/10.1210/jcem.81.6.8964834

Polacek I., Daniel E. E. (1971): Effect of $\alpha$-and $\beta$-adrenergic stimulation on the uterine motility and adenosine 3', $5^{\prime}$-monophosphate level. Can. J. Physiol. Pharmacol. 49, 988-998 http://dx.doi.org/10.1139/y71-137

Richter O., Kübler K., Schmolling J., Kupka M., Reinsberg J., Ulrich U., Wardelmann E. (2004): Oxytocin receptor gene expression of estrogen-stimulated human myometrium in extracorporeally perfused non-pregnant uteri. Mol. Hum. Reprod. 10, 339-346 http://dx.doi.org/10.1093/molehr/gah039

Sanborn B. M., Ku C.-Y., Shlykov S., Babich L. (2005): Molecular signaling through G-protein-coupled receptors and the control of intracellular calcium in myometrium. J. Soc. Gynecol. Investig. 12, 479-487 http://dx.doi.org/10.1016/j.jsgi.2005.07.002

Slater D. M., Dennes W. J., Campa J. S., Poston L., Bennett P. R. (1999): Expression of cyclo-oxygenase types-1 and-2 in human myometrium throughout pregnancy. Mol. Hum. Reprod. 5, $880-884$ http://dx.doi.org/10.1093/molehr/5.9.880

Soloff M. S., Alexandrova M., Fernstrom M. J. (1979): Oxytocin receptors: triggers for parturition and lactation? Science 204, $1313-1315$ http://dx.doi.org/10.1126/science.221972

Soloff M. S., Jeng Y. J., Copland J. A., Strakova Z., Hoare S. (2000): Signal pathways mediating oxytocin stimulation of prostaglandin synthesis in select target cells. Exp. Physiol. 85, 51S-58S http://dx.doi.org/10.1111/j.1469-445X.2000.tb00007.x

Trujillo M., Ausina P., Savineau J.-P., Marthan R., Strippoli G., Advenier C., Pinto F., Candenas M. (2000): Cellular mechanisms involved in iso-osmotic high $\mathrm{K}+$ solutions-induced contraction of the estrogen-primed rat myometrium. Life Sci. 66, 2441-2453 http://dx.doi.org/10.1016/S0024-3205(00)80004-1 
Wilson T., Liggins G., Whittaker D. (1988): Oxytocin stimulates the release of arachidonic acid and prostaglandin F $2 \alpha$ from human decidual cells. Prostaglandins 35, 771-780 http://dx.doi.org/10.1016/0090-6980(88)90149-9

Zhou X.-B., Lutz S., Steffens F., Korth M., Wieland T. (2007): Oxytocin receptors differentially signal via $\mathrm{Gq}$ and Gi proteins in pregnant and nonpregnant rat uterine myocytes: implications for myometrial contractility. Mol. Endocrinol. 21, 740-752

http://dx.doi.org/10.1210/me.2006-0220

Received: April 5, 2016

Final version accepted: May 31, 2016

First published online: October 27, 2016 